Germany, or any other country might be proud. Dr. Xanthoudidis has for several years past made important discoveries, and now Dr. Hatzidakis has discovered and is excavating an important Minoan palace at Tylissos, not far from Knossos, at the base of Ida. Great brazen bowls, the largest vase of obsidian (a single piece twelve inches high) yet discovered, and a remarkably bold and fine bronze statuette of a man in the Minoan saluting attitude of adoration, are only a few of the fine trophies that have come from Tylissos to the shelves of the really magnificent museum of Candia. The work at Tylissos continues under the direction of Dr. Hatzidakis.

The Museum of Candia may be described as the Mecca of students of the Greek Bronze age, though the Ashmolean at Oxford, thanks to the unremitting care of Sir Arthur Evans, is a very good second to

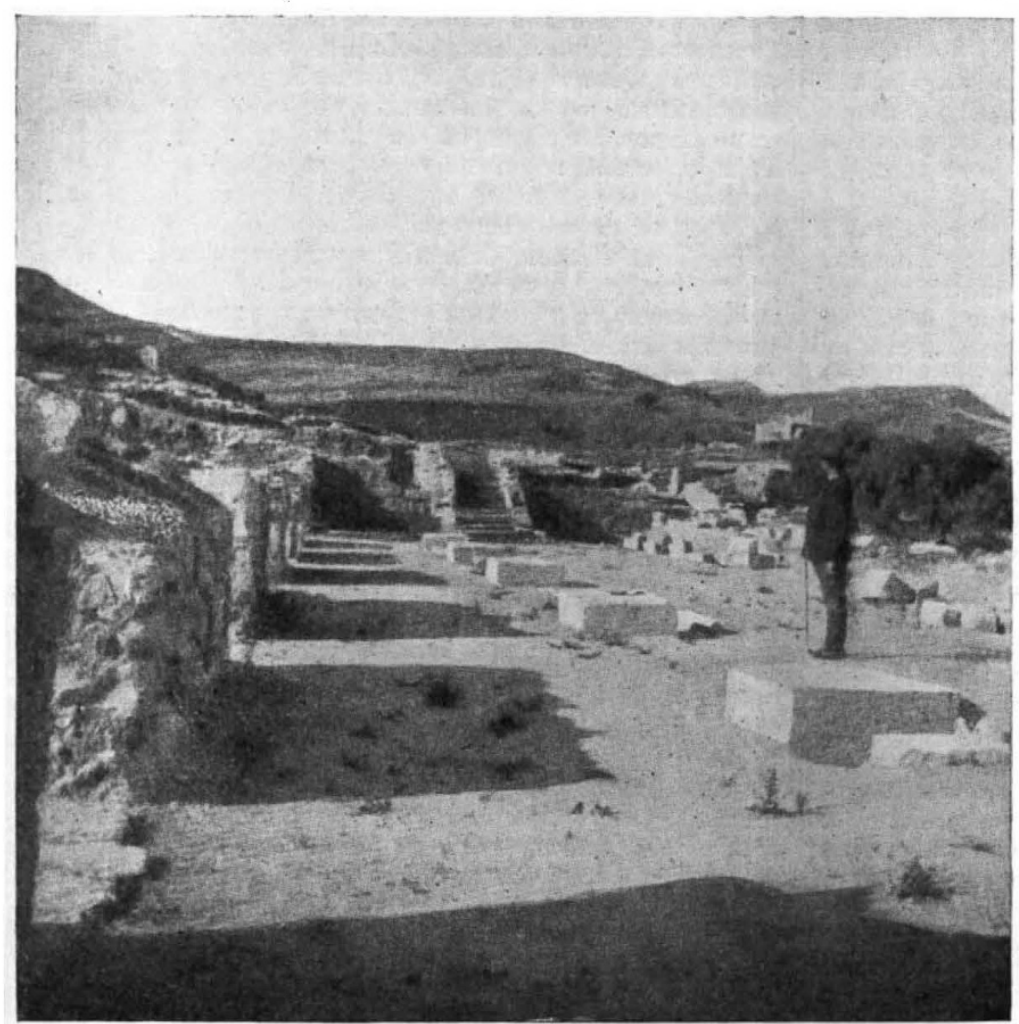

F1g. 3.-Agia Triada : the new Agora.

it, so far as Cretan antiquities are concerned, and the first vase room at the British Museum now contains a "Mycenæan" collection which, thanks chiefly to the results of past excavations of Minoan tombs in Cyprus, makes the British Museum by no means a bad third, while its Cretan collection also has now become quite important. The Museum of Athens proudly exhibits its trophies from "golden" Mycenæ and elsewhere in Greece, but of Cretan and Cypriote antiquities it has none.

The British School at Athens has again turned its attention to a Mycenæan site this year, having resumed its interrupted excavations at Phylakopi in the island of Melos. Interesting discoveries, especially of pottery, have been made. The German work at Tiryns last year produced most important results, especially remarkable being the remains of No. 2 I90, vor. 87$]$ a fresco depicting a boar-hunt, in which figure two women (or, more probably, in the writer's view, noble youths) riding to the hunt in a chariot. A fine representation of a woman in splendid robes has also been found. Reproductions of this fresco, from the accomplished hand of M. Gilliéron, junr., will soon be given to the world.

Elsewhere in Greece, though interesting results have been obtained by the French at Delos, the most remarkable discovery has been made this year at Corfu, where the Greek Archæological Society has discovered an archaic temple, with sculptures resembling the metopes of Selinus in Sicily. In view of the fact that ancient Kerkyra was a colony of Corinth, and Selinus of the neighbouring Megara, this resemblance is interesting. At the time of the discovery the German Emperor was in residence at his Corfiote palace of the Achilleion, and, thanks to his active interest in it, the excavation is to be continued under the distinguished direction of the leader of German archæology in the Levant, Prof. Dörpfeld (see Nature, vol. Ixxxvii., p. I49).

I bring this account to an end with a mention of the explorations of Messrs. Wace and Thompson for the English Macedonian Exploration Fund in the Elassona district of Turkish Thessaly, which will no doubt add much to our knowledge of the remarkable Neolithic culture of northern Greece, which has upset so many preconceived notions of the early history of Greek civilisation. It may be noted, in this connection, that Mr. F. W. Hasluck has just discovered a Minoan "bee-hive" tomb at Kirk-kilisse in the vilayet of Adrianople.

H. R. Hall.

\section{PROGRESS IN ELECTRIC LIGHTING, HEATING AND COOOKING.}

F LECTRICAL engineers are $E$ claiming-and are claiming with justice-that great advances from the industrial and commercial point of view have been made during the last year or two in electric lighting, heating and cooking; but the average man of science, who probably concerns himself more with general principles than with the detailed applications of physics, may wonder in what these great advantages ment of tungsten in place of carbon for the filaments of incandescent lamps, and the consequent improvement in efficiency from 4 to $I \frac{1}{4}$ watts per candle-power, dates back to five years ago, and will point out that in the present form of this lamp a tungsten filament is still used, heated to the same temperature, and consequently having the same light efficiency. As to electric heating, he may even be still more sceptical, for, when at school or college, he may have learnt that the energy of an electric current flowing continuously through a resistance is transformed into heat, and that no invention can make the heat generated greater than is represented by the square of the current multiplied by the resistance of the wire. It will, therefore, not be out of place to pass in review 
the actual improvements in detail which enable the electrical engineer to substantiate his claim that great progress has been made.

Taking the case of electric lighting first. The efficiency of the incandescent lamp depends entirely upon the temperature of the filament, if we neglect for our present purpose the hypothesis of selective emissivity of certain substances, which, although advanced from time to time, has never been completely established, and in any case would only slightly affect the accuracy of the above general statement. Tungsten, being more refractory than carbon, can be kept continuously at a higher temperature without volatilising, and a tungsten filament would give three times the light of a carbon filament for the same consumption of power and the same life. But as the specific resistance of tungsten is lower than that of carbon it was necessary to produce a finer filament than the carbon one, and to find a means of supporting a greater length of this fine filament in the lamp. These difficulties were at first only partly overcome. The filament of a 25 -c.p. 220-volt carbon lamp has a diameter of about $0^{*} 16 \mathrm{~mm}$., and a length of about $35^{\circ} \mathrm{mm}$., while the filament of a tungsten lamp of the same candle-power and voltage is about $0^{\circ} 02 \mathrm{~mm}$. in diameter and $830 \mathrm{~mm}$. long.

To produce pure tungsten in the form of a rod with a diameter in the order of a few hundredths of a $\mathrm{mm}$. it was necessary to mix it with other materials, to press or "squirt" a filament of the required diameter, and to eliminate the foreign substances by various processes, at the same time "forming" and strengthening the pure tungsten filament which was left. This resultant filament was exceedingly brittle, especially when cold, and it could only be made in short lengths, so that several separate loops had to be independently supported and joined in series in each lamp; obviously a delicate operation in view of the fragility of the filament and the difficulty of welding tungsten to other metals.

At first, therefore, the filament could only be made of small enough diameter and high enough resistance for comparatively high candle-powers, and for voltages not greater than IIo volts; and, in fact, when the first tungsten lamps were put on the market as articles of commerce only one diameter of filament was used, and the length varied according to the voltage, so that the buyer had to be satisfied with one particular candle-power of lamp suited to his voltage. Month by month and year by year, however, the manufacturing processes were improved, the filaments were made stronger, finer filaments were pressed and formed, and the methods of mounting them were bettered. The range of sizes and voltages was gradually increased, and during the first half of 1909 i6-c.p. Ioo-volt lamps and 32-c.p. 200-volt lamps with tungsten filaments were placed on the market, followed in the autumn of that year by a 25 -c.p. 200 -volt 32-watt lamp.

With this, the limiting size of a squirted filament seemed to have been reached, but in the meantime painstaking research work had been carried on in the laboratories of the chief lamp manufacturers, with the object of finding a process for actually drawing tungsten in the form of a wire. This has now been finally accomplished on a commercial scale, and during the last two months three of the leading incandescent lamp manufacturers in this country have already practically "scrapped" their comparatively new filament presses used for the squirting process, and are making their lamps with filaments of tungsten wires. The new wire filament has an enormously greater strength, and as in addition it can be used in the lamps in one continuous length without joints, the robustness of the lamp has been so improved that it is as great as that of one with an ordinary carbon filament. Finally, it has been already found possible to produce finer filaments of drawn wire than by the squirting process, and, as has already been announced in our columns (September 28, p. 420), at the opening of the Electrical Exhibition at Olympia on September 23, a 16-c.p. 220-volt 20-watt Osram lamp was shown, as an article of commerce, with a filament only about $0^{\circ} 015 \mathrm{~mm}$. in diameter.

During the various stages of the introduction of the metal filament lamp, the electrical engineer set himself the task of making the utmost use of the economy which it occasioned in the consumption of electrical energy. For equal light, one-third of the energy was being consumed as with the carbon filament lamp, and the consequent cheapening of electric light opened a much wider field. and brought it within reach of the smaller householder. There were, however, two obstacles to overcome: first, the fact that the metal filament lamps for the usual town-lighting voltages were only to be obtained in comparatively large sizes, so that although the consumer obtained three times the light at the same cost, he could not light a small room at one-third of the cost; and, secondly, the expense of wiring a house for electric light acted as a deterrent to the small householder.

The first of these difficulties was overcome, in alternating-current systems, by the interposition of a small transformer or "auto-transformer" between the consumer's main switch and his lamps. A voltage of 25 or 50 could thus be obtained, for which pressures metal filament lamps down to the smallest candlepowers have been obtainable during the past four years. A wastage of electrical energy is, however, liable to occur when no lamps are on, unless the consumer then turns off the supply at his main switch, for otherwise magnetising current is passing through the primary of the transformer all day long, whether lamps are switched on or not. To prevent this waste automatic switches have sometimes been employed to disconnect the transformer when all lamps are extinguished, and to reconnect it as soon as a lamp is turned on.

One of the latest types of these (made by Messrs. Muirhead and Co.) is shown in Figs. I and 2 . In this case an auto-transformer is employed; that is to say, a coil connected across the mains with a tapping at a point corresponding to the pressure required for the secondary circuit. The construction of the switch is clear from the general view and diagram. When no lights are on, the main circuit of the auto-transformer is open at the mercury cup I. As soon as one lamp is switched on, a circuit is established through the coil marked starting coil, and the "auxiliary" coil and "main" coil in series, and the core seen in the two illustrations is sucked into the coil, making contacts $I$ and 2 . This connects the auto-transformer to the mains at contact $I$, and also short-circuits the starting coil at contact 2. When a few more lamps are in circuit, bringing the current up to 2.2 amperes, the core has been sucked in further, and contact 3 is made, short-circuiting the "auxiliary" coil and leaving the main or retaining coil only in circuit. The object of successively short-circuiting the first two coils is to diminish the voltage drop. On the lamps all being switched off, the arm falls by gravity, and the auto-transformer is out of circuit.

One of the largest items in the wiring of houses is the cost of fixing the steel tubing or wooden casing in which the wires are placed. In those houses where surface work is not objected to, use is now frequentlv made of metal-encased wires, which are simply fixed on the walls by metal saddles. The metal casing is 
in the form of a tube of thin tinned copper or a lead alloy pressed round the insulated wire, and-forming an integral part of it. When low-voltage wiring is supplied through a double-wound transformer, the outer metal sheathing of the wire is used as a return conductor; in the case of the lead-covered wire there is a thin copper tape under the lead to improve the conductance. For continuous current and houses supplied through an auto-transformer, a twin wire is usually employed, the two wires being under one

FIG. x.-Automatic Transformer Switch (cover removed).

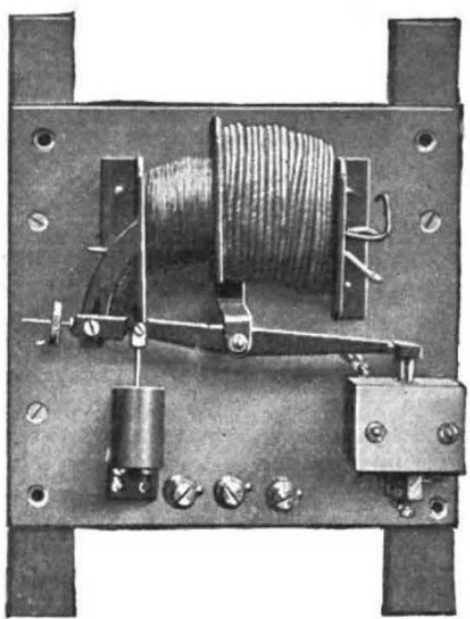

sheath. In both cases it is essential that the outer sheath shall be mechanically continuous; in the concentric system this is obvious, and in the twin system the continuity of $t h e$ casing, which is then earthed at one end, is necessary to secure immunity from shock or fire in case of leakage. The necessary "bonding" of the sheathing, therefore, forms part of the "system," and various simple arrangements a re used for connecting the wires to the fittings, which effectually prevent this bonding from being omitted.

In comparison with the triumphs that have been accomplished in the laboratory and works in connection with lamp manufacture, the improvements in heating and cooking apparatus will appear slight. They are largely pure improvements in constructional details. The success of electric cooking has been

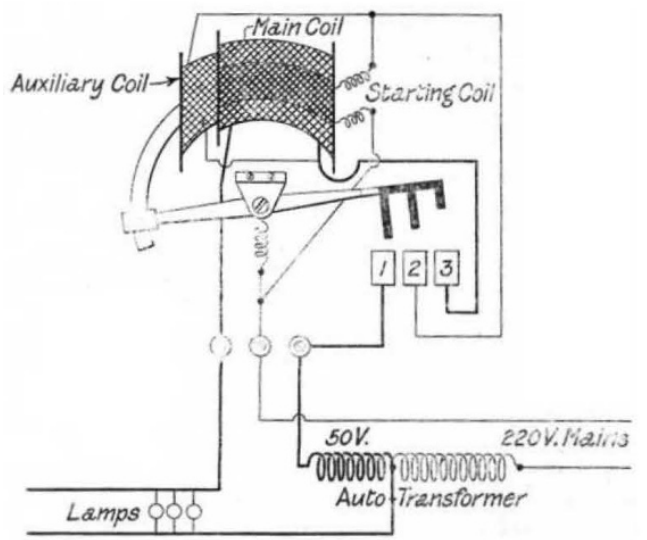

FIG. 2.-Diagram of Automatic Transformer Switch

almost entirely due to the possibility of bringing the actual heating element in the closest possible proximity to the object to be heated, so as to heat nothing clse than the actual surfaces required for the cooking operation; this is, of course, not possible to such a degree either with coal or gas cooking. To illustrate this two of the simplest examples may be taken. Fig. 3 is a "table toaster" shown open. The heating element is a ribbon of high-resistance alloy wound spirally on strips of mica. This glows with No. 2 I9O, VOL. 87] a dull-red heat when current is turned on. The bread is placed in the removable sides (one only is seen in the illustration), a piece on either side of the heater, and these are closed up so that the bread is held vertically, and parallel to the surface of the heater, with only a very short space between. As a result the bread is toasted absolutely evenly, and with no loss of heat at all. Fig. 4 is a section of the lower part of an electric kettle, and it is seen that the

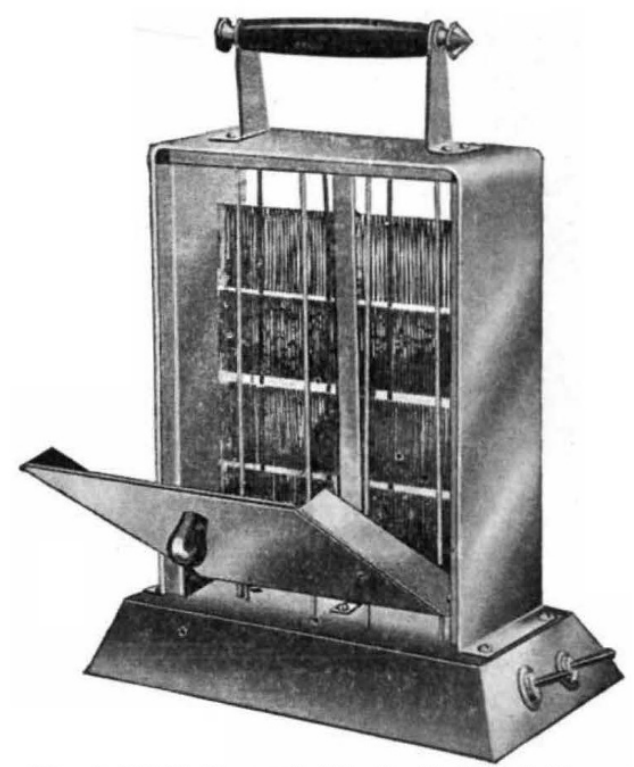

FIG. 3.-Electric "Table Toaster." (Simplex Conduits, Ltd.)

heating element projects into the bottom of the kettle, and is practically surrounded by the water.

In the larger cooking apparatus similar means are taken to bring the heating elements exactly where they are wanted, and to reduce the amount of heat lost by radiation and convection to a minimum. For instance, in most forms of electric oven at least three of the sides contain heating elements quite close to the interior surface; in nearly all makes the lagging is very thoroughly carried out, while others rely to some extent on giving the outside of the apparatus a bright surface to reduce radiation. It has also been proved by experiment that in roasting a joint in an electric

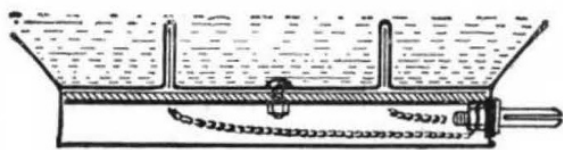

Fig. 4.-Arrangements of heating elements in Kettle. (Simplex Conduits, Ltd.)

oven, owing to the more even distribution of the heat there is less shrinkage of the meat, so that it retains its gravy; it appears that the smallest possible diminution of weight in a joint during cooking is an object aimed at by cooks and housewives, and that in this respect the electric oven has the same superiority over the gas oven as the gas oven has over the ordinary coal-fired kitchen range. The precision with which the heat can be regulated by switching on or off the heating elements as required is also a great advantage both as regards good cooking and absence of waste, and several makers adopt a series-parallel arrangement of connections and switching, so that all the elements are utilised, whether at full, half, or quarter heat, and there is absolute uniformity of temperature over the whole of the heating surface. 
Great improvements have also been effected in the heating elements themselves. In the earlier apparatus it was customary to use coils of wire coated with or embedded in enamel, but trouble was experienced owing to the different coefficients of expansion of the wire and the enamel, and consequent cracking and gradual disintegration of the latter, due to unequal expansion. Enamel insulation has been considerably improved in this respect now, and some makers employ it with success, but the favourite method is to wind the high-resistance metal in the form of ribbon on mica strips, or to use flat strips of metal wound edgewise and separated by mica. One maker employs spirals of wire in quartz tubes, and another has for long been particularly successful with strips of mica upon which very thin films of metal have been deposited.

An interesting attachment to a water-boiler (made by the Bastian Electric Heating Syndicate) is shown diagrammatically in Fig. 5. Above the chamber con-
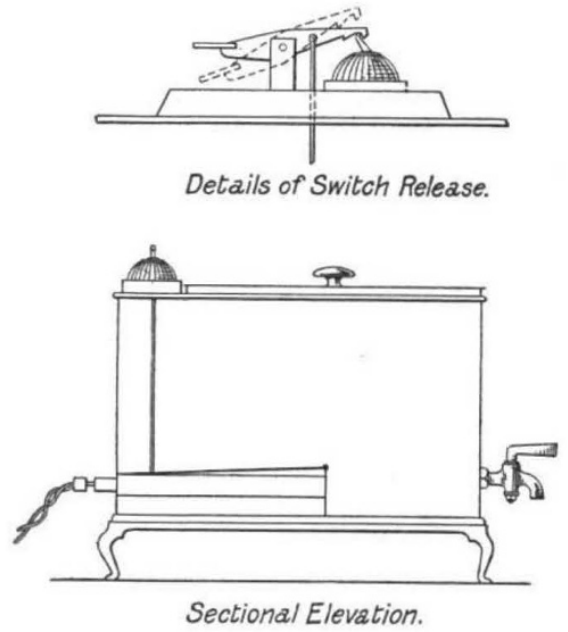

F1G. 5.--Water Heater with Automatic Switch.

taining the heater is a light, hinged metal flap, upon which bears the end of a rod connected to a catch lever holding the switch in the "on" position. The bubbling of the water when boiling causes the flap to rise, releasing the switch and thus turning off the current.

\section{MANKIND—FROM THE PLIOCENE TO THE PRESENT.}

URING the last forty years the opening period of mankind has receded further and further into the past. At first we were content to count the years in thousands, then in tens of thousands, and now nothing less than hundreds of thousands is regarded as sufficient to cover the known period of man's existence on the earth.

The three works noticed here cover the whole of the human period so far as it is yet known. Dr. H. v. Buttel-Reepen deals with the Europeans of the Pleistocene or Glacial period, to which, following the teaching of Dr. A. Penck, he assigns a round half1 "Aus dem Werdegang der Menschheit. Der Urmensch vor und während der Eiszeit in Europa." Von Dr. H. v. Buttel-Reepen. Pp. vi+

139+109 figures in text +3 tables. (Jena: Gustav Fischer, rgrr.) hausen speziell des anthropologischen Monographie des Kantons Schaffhausen speziell des Klettgaues. Von Franz Schwerz. Neue Denkschriften der schweizerischen naturforschenden Gesellschaft, Bd. xiv., pp. 83-29280 figures + 1 map +87 tables. (Zürich: Zürcher \& Furrer, rgio.)

char Prof.

Lubos Niederle. Traduit du Tchéque par Louis Léger. Pp. xii +23I + I map. NO. 2 I90, VOL. 87$]$ million of years. Dr. Franz Schwerz takes up the story where Dr. H. v. Buttel-Reepen leaves off, and describes the various races which have inhabited his native canton of Schaffhausen since the Neolithic period began-one which he regards as commencing about 25,000 years ago. The third work, by Prof. Niederle, of the University (Tchéque) of Prague, is concerned with events which lie within the Christian period-the expansion and fate of the Slavonic race into south and central Europe and into Asia.

The three works are very different in nature; Dr. v. Buttel-Reepen's small monograph is a concise and excellent summary of the facts and theories relating to mankind in Europe during the Glacial period; it is the best of the many books that have lately appeared in Germany to supply a popular demand for information concerning early man, and is richly illustrated. Dr. Scherwz's monograph represents the results of personal research, and reflects the exact, elaborate, and painstaking methods of the Zurich school of anthropologists. Prof. Niederle's book is a stock-taking of the Slavonic race; he estimates that there were $139,000,000$ Slavs at the commencement of the present century, more than 20,000,000 of whom occupy territories outside Russia, and are a continual cause of political unrest in central and eastern Europe.

It is the anthropological rather than the political data of Prof. Niederle's writings which interest us here. He appears to supply the answer to a problem which has puzzled Dr. Schwerz and has been an enigma to anthropologists in every country, especially in England. The problem concerns the source and supply of the brachycephalic races of central Europe and their sporadic appearance in Britain. The oldest human remains yet found in Schaffhausen-a canton almost surrounded by German territory-are those of Schweizersbild-remains which supplied Prof. Kollman, of Basle, with the basis for his famous theory of a pygmy prehistoric race in Europe. There can be absolutely no doubt that the Schweizersbild Neolithic men are identical with the Neolithic English described by Huxley as the "river-bed type"-people of rather low stature and with small heads, somewhat compressed from side to side and falling in the dolichocephalic group. The inhabitants of Schaffhausen soon after the beginning of the Christian era were also a long-headed people, which Dr. Schwerz associates with the Reihengräber of south Germany. The modern inhabitants of Schaffhausen are eminently short-headed, but as to how and when the short-headed people replaced the long-headed Dr. Schwerz can give no answer.

The change in head form in Schaffhausen is most probably due to a Slavonic permeation. In colouring and head-form the modern inhabitants of Schaffhausen are Slavonic. As far back as history and tradition can take us Russia has been the home of the greatest and most homogeneous mass of brachycephalic humanity. Prof. Niederle paints a picture of the exodus of the Bulgarians, Servians, Slovenes, Slovoques, Tschéques, Lusaciens, and Poles, from the parent stock in Russia, and their absorption in the German-speaking peoples.

We may be certain that what has taken place in historical times-a continuous exodus and absorption of the round-headed Slavonic stock-had been at work during the greater part of the Neolithic period, if not earlier. A round-headed race is not known to occur in western Europe until the latter part of the Paleolithic period. There is every reason to regard the shortheaded races of mankind as comparatively recent products of evolution; every known example of Glacial and early post-Glacial man, with the possible exception of some Krapina people, is of the long-headed 